BOOK REVIEW: DE PONTE, Maria \& KORTA, Kepa (eds.). Reference and Representation in Thought and Language (Oxford, Oxford University Press, 2017, 304 pages)

\title{
Filipe Martone
}

University of Campinas

Department of Philosophy

Campinas, SP

Brazil

filipemartone@gmail.com

\section{Article info}

CDD: 401

Received: 04.07.2018; Accepted: 04.07.2018

DOI: http://dx.doi.org/10.1590/0100-6045.2018.V41N2.FM

\section{Keywords:}

Reference

Representation

Philosophy of Language

Philosophy of Mind

Direct Referenc

\begin{abstract}
In this review, I try to present and discuss the main elements of each chapter of the book as briefly and instructively as possible. The first group of chapters deals with various issues about language, and the second group focuses on thought.
\end{abstract}

This book explores many different issues and aspects of the various ways by which we talk, think and represent the world. On the side of language, philosophers and linguists offer new insights on proper names, descriptions, indexicals and anaphora which will interest anyone working on semantics, especially in the direct reference framework. On the side of thought, the book contains chapters on the representation of time, cognitive dynamics, selfhood, and on de se attitudes. Mediating between them is a chapter on salience, a now much discussed notion that concerns both language and thought. In what follows, I present the central 
elements of each chapter as succinctly as possible, commenting briefly on them when I see fit.

The first two chapters deal with the prototypical referring expressions, i.e., proper names. In "Names, predicates, and the object-property distinction", Genoveva Martí takes issue with predicativism ${ }^{1}$. Roughly, predicativists hold that the semantics of names do not differ essentially from that of common nouns like 'horse' or 'refrigerator'. Just like those nouns, names express a property, namely, the property of bearing the name. For Martí, however, predicativism is wrong at a fundamental level: it fails to capture how language expresses the basic metaphysical distinction between objects and properties. The grammatical subject-predicate distinction is not enough. Descriptions in subject position can single out objects all right, but they do so by appealing to their properties. Only truly referring names can abstract objects from their attributes. As she puts it, names are devices for expressing "the separation of the object from its properties - from all of its properties - that is required to distinguish the object, the substance, from its attributes" ( $p$. 16). Predicativism does not give us that.

Marti's chapter discusses some of the central aspects of direct reference in an engaging manner, and it offers us plenty to discuss despite its short length. One thing needs clarification, though. She appears to conflate the notion of an object (or substance) with that of a substratum (or bare particular). In the passage quoted above, for example, she seems to think that the notion of an object is that of a thing abstracted from all its properties. But this is not, strictly speaking, the notion of an object, but of a substratum. If this is right, then the underlying metaphysics referential semantics would capture is that of substratum-property distinction. But I doubt this is correct. It is prima facie reasonable to be a referentialist and a bundle theorist or a

${ }^{1}$ Fara (2015) is the most worked out defense of predicativism to date.

Manuscrito - Rev. Int. Fil. Campinas, v. 41, n. 2, pp. 123-136, abr.jun. 2018. 
hylomorphist, and both views eschew substrata. But if an object is not something abstracted from all its properties, it is not obvious why predicativists should feel threatened. Her other objection, that predicativism presupposes that names are referential devices (pp. 18-19), however, is much more compelling.

Eros Corazza, in his rich contribution "Proper names: gender, context-sensitivity, and conversational implicatures", discusses how names can systematically convey more information than merely their semantic content, and how that information is exploited by anaphoric reference. All this without abandoning Millianism, because this information is non-semantic: it is extrinsic or stereotypical, and hence not part of truth-conditional content. For example, the semantic content of 'Sue' is just an individual, but the name also imparts the information that its referent is female. That information, however, is cancellable, as illustrated by Johnny Cash's song A Boy Named "Sue": Sue's dubious father does not violate any grammatical or semantic rules by naming him so. Thus, stereotypical information may be allocated in "the category of [Gricean] generalized conversational implicatures" (p. 28). We often exploit stereotypical information in anaphoric reference, as when we say 'Sue said she isn't coming today', even if we are unsure of Sue's gender. Stereotypical information, then, provides us with default interpretations in anaphoric reference. Corazza also discusses the context-sensitivity of gender-silent names like 'Chris' and 'Kim', as well as other relevant issues often neglected in philosophy of language. In sum, the chapter is an example of how rich and resourceful - and not the barren landscape oftentimes depicted by its opponents - Millianism can be.

The next three chapters focus on indexicals. As the editors say, "they offer key insights on self-knowledge, action, consciousness, subjectivity, and so on. Understanding them is essential for understanding both reference and representation" (p. 5). In "Indexicals and 
undexicals", John Perry offers a new account of good old indexicals like 'today' and 'tomorrow'. In short, Perry analyzes what he calls undexical uses of these expressions. An undexical use occurs when the input for the arguments of the relevant expression does not come from the Kaplanian context (the 4-tuple of agent, time, location and world), but rather from a different source. Consider:

(1) Whenever we are in Ireland, the local bars miss us.

(2) Wherever one is in Ireland, the local bars are friendly.

(3) I'm going to be in Cushendale next week. The local bar is very friendly.

In (1), the input location for 'local' comes from the context of the utterance, and so 'local' functions indexically. In (2), the input is provided by the quantifier 'wherever', and so 'local' functions like a bound variable. In (3), the antecedent sentence provides the relvant location for 'local', and so it is used anaphorically. Thus, 'local' is used undexically in (2) and (3). Perry argues that the same phenomenon occurs with other indexicals like 'past' and 'tomorrow': when their inputs are supplied by the context, they function indexically; when not, they function undexically, as in 'Never put off until tomorrow what you can do today' (this example is discussed at length). Also, he points out that expressions have a default indexical use when they are normally used indexically rather than undexically (e.g. 'today'). In the final part of the chapter, Perry discusses the cognitive advantages of undexical uses and how they are based on default indexical uses. He also introduces the concepts of roles and of role linking, and claims that intelligent life is based on them (p. 53). Unfortunately, his discussion is rather brief for too deep an issue; it would definitely benefit from a longer treatment elsewhere.

Kent Bach's "Reference, intention, and context: Do demonstratives really refer?" defends the unorthodox view that demonstratives (e.g. 'this' and 'that') do not have 
semantic reference, and hence are not genuine contextsensitive expressions. For Bach, there is a fundamental difference between demonstratives and automatic indexicals like 'I' or 'today'. Automatic indexicals are genuinely contextsensitive and semantically refer because their meanings suffice to determine reference as a function of context. They refer on their own, so to speak. Demonstratives do not. Their meanings are insufficient to determine reference; at most, they restrict what can be literally referred to. For instance, the meaning of 'that dog' restricts reference to dogs, but it cannot determine a particular dog by itself. In Bach's terms, we refer by an expression when the expression itself is able to refer; we refer with an expression when we use it merely as an aid to reference. Because demonstratives do not have semantic reference, we only refer with them, not by them. The leading alternative to this picture is semantic intentionalism. Basically, semantic intentionalism holds that the meanings of demonstratives are sensitive to speaker intentions, and that these intentions make demonstratives semantically refer ${ }^{2}$. However, Bach argues, speakers only intend to refer with a demonstrative; they do not also intend for the object to be the semantic value of the demonstrative. The first intention has no semantic relevance, and thus cannot help intentionalism; the latter would make it work, but it is simply not part of the mechanics of demonstrative reference.

Bach's thesis has serious implications for standard truthconditional semantics, for demonstratives would not make any determinate contribution to semantic content. He suggests that the same problem plagues "other putative context-sensitive expressions and constructions, such as gradable adjectives, epistemic modals, predicates of personal taste, relational nouns, genitive phrases, noun-noun pairs, and quantifier phrases" (p. 59). His argument, then, has far-

${ }^{2}$ Cf. Stokke (2010), King (2014).

Manuscrito - Rev. Int. Fil. Campinas, v. 41, n. 2, pp. 123-136, abr.jun. 2018. 
reaching consequences for the debate on contextualism. I wonder, however, whether it affects the so-called BareBones theory of demonstratives ${ }^{3}$. Basically, it holds that the context provides objects, not intentions, as inputs for demonstratives. Bare-Bones semantics, then, is intentionfree, both in context and in character. Hence, it is not obvious that Bach's argument applies to it as well.

In "Semantic complexity", Maite Ezcurdia offers an insightful discussion of what distinguishes referring from quantificational noun phrases. The standard distinguishing criterion is that referring expressions are rigid by their nature, whereas quantificational expressions are not. Stephen Neale adds another criterion: referring expressions must also be semantically unstructured. This is what Ezcurdia calls the "noun phrase thesis" (NPT). For NPT, noun phrases are either semantically unstructured rigidly referring expressions or semantically structured restricted quantifiers. But what about complex demonstratives (e.g. 'that man in the corner')? They seem to refer, but their form strongly resembles that of descriptions. Are they referring or quantificational? For Neale, they are referring. Yet, if NPT is true, they must be semantically unstructured, and hence the nominals contained in them are semantically otiose. For Ezcurdia, however, this is implausible. She argues that we have no good reasons to hold NPT, and that complex demonstratives can be both referring and semantically complex. She claims that we must distinguish two kinds of semantic complexity: one, exhibited by quantificational expressions, shows up in the truth-conditions; the other, exhibited by complex demonstratives, stays only at the level of linguistic meaning. These two kinds of complexity are related to the two semantic roles nominals can play in noun phrases: in quantificational phrases, their role is predicative, i.e., they restrict the range of the quantifier; in referring phrases, their role is individuative, i.e., they determine the

${ }^{3}$ Cf. Caplan (2002) and Predelli (2012).

Manuscrito - Rev. Int. Fil. Campinas, v. 41, n. 2, pp. 123-136, abr.jun. 2018. 
extension of an expression for further predication. Hence, the nominals contained in complex demonstratives are not semantically otiose; they just have a different semantic function.

Ezcurdia's chapter is rich, well-argued and generous to Neale's thesis. The only thing I want to point out is that the difference between predicative and individuate roles for nominals could have been spelled out in a bit more detail. Ezcurdia claims that nominals in complex demonstratives are not predicative because "they are not saying something about an object that an expression $[\ldots]$ has previously selected. Rather they aid in the selection of the object itself [...]" (p. 81). But the nominals in a description in subject position seem to be doing this as well. In other terms, they too select an object so that the grammatical predicate can 'say something about' it; they just do it by a different semantic mechanism. In a sense, then, they are also individuative. Thus, the notion of 'not saying something about a previously selected object' seems too general to distinguish the individuative role from the predicative role.

In the chapter "Donnellan's misdescriptions and loose talk" Carlo Penco argues against "the standard view" of definite misdescriptions. According to this view, we cannot state something true in a referential use of a definite description if the description fails to fit; whatever truth is conveyed is conveyed by implicature. Penco, however, thinks this is mistaken: we can indeed state a truth even if nothing fits the description. He calls this thesis "Donnellan's intentional strong claim" (DISC), and offers a defense of it. Donnellan's insight, according to Penco, is that referential uses involve a type of social intention, an "intention to use a descriptive content fit for the context of utterance" (p. 112). This intention cannot be divorced from what speakers should expect their audience to understand in the relevant context. And, crucially, this intention is part of what is said, of what is stated, and not merely of what is implicated. Hence, Penco claims, we can already find in Donnellan a 
theory of loose talk, as discussed by Sperber and Wilson (1986), and a rejection of the Gricean "two-stage" analysis according to which we state a falsity and implicate a truth. As Penco notes, this reading makes Donnellan a precursor of contextualist ideas. Based on Donnellan's isights, Penco argues that "what is said by a referential description depends on the grade of looseness required by the context" (p. 119), and that "looseness is motivated by the pursuit of relevance" (p. 115). All in all, it does not matter whether Penco's reading of Donnellan is accurate or not; his proposal is original and interesting in its own right and deserves further discussion.

The linguist Yan Huang is the author of the next contribution, entitled "Pre-semantic pragmatic enrichment: The case of long distance reflexivization". Consider this sentence:

(4) $* J_{0 h n}$ said that Bill loved himself1

In English, (4) is ungrammatical: the pronoun cannot be bound by 'John'. However, in languages such as Japanese, Chinese and modern Greek, for example, this long-distance binding is allowed. That is, reflexives can be systematically bound outside their local syntactic domains. Marshalling evidence from a variety of languages, Huang explains the phenomenon of long-distance reflexivization with his version of the neo-Gricean pragmatic theory of anaphora. In broad strokes, he argues that long-distance binding is "pragmatically enriched for reference pre-semantically" ( $p$. 126), and thus helps determining what is said.

In "The interplay of recipient design and salience in shaping speaker's utterance", Istvan Kecskes employs his sociocognitive approach (SCA) to account for the mechanisms of speaker's utterance production. Very roughly, SCA aims to integrate and explain the relation between the individual traits (prior experience; salience; egocentrism; attention) and the social traits (actual situational 
experience; relevance; cooperation; intention) that are brought to bear in communication exchanges. More precisely, Kecskes wants to show how the interaction between subconscious salience and recipient design - the model a speaker builds of the hearer's relevant knowledge in the context - shape speakers' production, and why "speakerhearer rationality should include not only cooperation but egocentrism as well" (p. 161). The concept of salience has recently drawn a lot of attention in various debates including in the debate about indexicals and demonstratives -, and Kecskes makes a valuable contribution to our understanding of it.

In the following chapter, "New thoughts about old facts", María de Ponte and Kepa Korta point out what they take to be some mistakes in Arthur Prior's argument against B-theories of time (i.e. theories holding that pastness, presentness and futurity are not objective features of reality). The gist of Prior's argument - and of many others like it - is that B-theories offer "no grounds for tensed thoughts and tensed emotions" (p. 164). Prior asks us to consider which of the following sentences we would use after a root canal operation:

(5) Thank goodness the root canal is over [now].

(6) Thank goodness the date of the conclusion of the root canal is Friday, June, 1954.

(7) Thank goodness the conclusion of the root canal is contemporaneous with this utterance.

For him, only (5) is adequate. Why? Because only the proposition expressed by (5) involves the property of being over (an A-property). Thus, to make sense of why we say (5), and not (6) or (7), we must count A-properties as objective features of reality. In short, Ponte and Korta read Prior's argument as being committed to three theses:

i. Utterances (5)-(7) express different propositions. 
ii. Utterances (5)-(7) are associated with different thoughts. iii. The proposition related to utterance (5) and its associated thought require the existence of an A-property of events (p.170).

Ponte and Korta partly agree with (ii), but reject (i) and (iii). First, being referentialists, they claim that sentences (5)(7) express the same proposition. Nevertheless, the way in which (5)-(7) express this proposition is different. As they put it, these sentences "are associated with different motivating thoughts (some of them A-thoughts, others Bthoughts) and present different cognitive routes for their respective audiences" (p. 172). They have different cognitive significance, but the same referential content. This is why they can express different thoughts. Second, Ponte and Korta argue that the move from the fact that we have tensed thoughts and emotions to the reality of tensed properties is unjustified and superfluous. In sum, their chapter is an attempt to clarify Prior's argument and undermine its supposed ontological import by showing how the puzzling phenomenon can be explained by a more sophisticated epistemic and semantic theory. In fact, it is hard to see how linguistic and epistemic considerations can reveal something about the nature of time. Ponte and Korta's thorough effort to untangle these issues is a welcome antidote to this sort of idea.

In "Cognitive dynamics", François Recanati develops and clarifies several aspects of his influential theory of mental files. In broad strokes, Recanati's view is that mental files can play some of the roles of Fregean senses: they determine reference, they explain cognitive significance, and they enable coreference de jure. They determine reference relationally, i.e., in virtue of standing in some relation to the file's reference, and not satisfactionally. This allows them to contain misinformation and still refer to the same thing. The different cognitive significance of 'Hesperus is Hesperus' and 'Hesperus is Phosphorus' is explained by the 
deployment of different files: in the first case, the subject deploys the same file twice, while in the second two distinct but coreferring files are deployed. Finally, coreference de jure is enabled when the subject deploys the same file in a chain of reasoning: it explains why the inference from 'Hesperus is bright' and 'Hesperus is a star' to 'Hesperus is a bright star' is warranted and rational. Onofri (2015) and Ninan (2015), however, object that mental files cannot explain cognitive significance and enable coreference the jure simultaneously. Recanati stands by his position and thoroughly addresses their worries.

The last two chapters tackle the issue of selfrepresentation. In "The property theory and de se attitudes", Wayne Davis argues against the so-called property theory of de se thoughts, originally proposed by Lewis and Chisholm, and recently advocated by Neil Feit ${ }^{4}$. The problem this theory attempts to solve is the following. An amnesiac Lingens can have the belief that he himself is lost while not believing that Lingens is lost. We would express this unfortunate situation with these sentences:

(8) Lingens believes that he himself is lost

(9) Lingens believes that Lingens is lost

The problem is that, if attitudes are taken to be dyadic relations between subjects and propositions, and propositions are taken to be singular propositions or sets of possible worlds, then both sentences express the same relation to the same proposition. The special character of the de se attitude is missing. To solve this, the property theory denies that believing is a propositional attitude; rather, believing is seen as self-ascribing a property. Davis, however, thinks this move fails to yield a satisfactory account of attitudes, and offers his own account. First, he puts forth ten

${ }^{4}$ E.g.: Feit (2008).

Manuscrito - Rev. Int. Fil. Campinas, v. 41, n. 2, pp. 123-136, abr.jun. 2018. 
objections against the property theory. Second, he argues that we should take attitudes to be relations to conceptual propositions, i.e., entities made up of concepts, and not to objectual propositions, i.e., singular propositions or sets of possible worlds. In addition, he claims that part of what made the problem of de se attitudes "seem insoluble [...] was the erroneous Fregean assumption that 'conceptual' elements must be descriptive" (p; 214). For Davis, the missing element in the explanation is a non-descriptive indexical self-concept. Thus, de se attitudes differ from other attitudes precisely because they are attitudes towards a conceptual proposition having an indexical self-concept as constituent.

In the last chapter, entitled "Selfhood as selfrepresentation", Kenneth Taylor proposes a middle ground between Cartesian and eliminativist/fictionalist accounts of the self. Contrary to Cartesians, he rejects the existence of a metaphysical sui generis entity that is supposed to be the self (something akin to a thinking substance); contrary to eliminativists/fictionalists, he believes that "there really and truly are beings organized as selves" (p. 225-6). For Taylor, selves are just beings psychically arranged in such a way that they bear the property of selfhood. And bearing selfhood consists in having the very special capacity to have selfrepresentations. Taylor's central idea is that selfrepresentations are distinct from other representations not because of what they represent, but because of how they represent it. Thus, for Taylor, to bear selfhood is not to be in possession of some mysterious inner entity or to have a "mental CEO" that constitutes the content of selfrepresentations. It is rather to have "the capacity to deploy [...] a de se device of explicit coreference" (p. 224, fn. 1). Taylor frames his position in a broader context, discussing Locke's, Hume's and Kant's views on the matter.

The editors of Reference and Representation in Thought and Language can only be commended for taking the pain to organize this volume. Its major merit is, to me, the great diversity of the themes discussed in the chapters. The 
selection admirably shows how issues surrounding reference go well beyond traditional topics in semantics, and how they intersect (or fail to intersect) with deep philosophical problems in metaphysics and in the philosophy of mind. And when it comes to traditional problems in semantics, the chapters offer novel solutions and often discuss underexplored aspects of our referential devices in an engaging and sophisticated manner. Anyone working on how language and thought relate to the world will surely enjoy this book.

\section{References}

CAPlan, B. 2003. "Putting Things in Contexts." Philosophical Review 112

(2):

191-214. https://doi.org/10.1215/00318108-112-2-191.

FARA, D. G. 2015. "Names Are Predicates." Philosophical Review 124 (1): 59-117. https://doi.org/10.1215/00318108-2812660.

FEIT, NEIL. 2008. Belief about the Self: A Defense of the Property Theory of Content. Oxford; New York: Oxford University Press.

KING, JEFFREY C. 2014. "Speaker Intentions in Context: Speaker Intentions in Context." Noûs 48 (2): 219-37. https://doi.org/10.1111/j.1468-0068.2012.00857.x.

Ninan, Dilip. 2015. “On Recanati's Mental Files.” Inquiry 58 (4): 368-77. https://doi.org/10.1080/0020174X.2014.883751.

ONOFRI, ANDREA. 2015. "Mental Files and Rational Inferences." Inquiry 58 (4): 378-92. https://doi.org/10.1080/0020174X.2014.883748.

PONTE, MARÍA DE, and KePA KORTA, eds. 2017. Reference and Representation in Thought and Language. First edition. 
Oxford Linguistics. Oxford, United Kingdom: Oxford University Press.

PREDELli, STEFANO. 2012. "Bare-Boned Demonstratives." Journal of Philosophical Logic 41 (3): 547-62. https://doi.org/10.1007/s10992-011-9183-5.

Sperber, DAN, and Deirdre Wilson. 2001. Relevance: Communication and Cognition. 2nd ed. Oxford; Cambridge, MA: Blackwell Publishers.

STOKKE, A. 2010. "Intention-Sensitive Semantics." Synthese 175 (3): 383-404. https://doi.org/10.1007/s11229009-9537-5. 